\title{
WHETHER WE NEED EMOTIONS IN BUSINESS OR NOT
}

\author{
Maia Akhvlediani ${ }^{1}$, Zurab Mushkudiani², Sophio Nikabadze ${ }^{3}$
}

${ }^{1,3}$ Akaki Tsetereli State University, Kutaisi, Georgia

${ }^{2}$ Batumi Navigation Teaching University, Batumi, Georgia

e-mails: ${ }^{1}$ m.akhveldiani@atsu.edu.ge, ${ }^{2}$ z.mushkudiani@bntu.edu.ge, ${ }^{3}$ sopiko.mikabadze@atsu.edu.ge

Received: 01 March 2020; Accepted: 01 May 2020; Published: 13 June 2020

\begin{abstract}
Background: Modern areas of applied psychology, including management psychology, traditionally distinguish two main groups of organizational efficiency indicators: productivity and socio-psychological. Productivity indicators, volume, and quality of manufactured products, the intensity of production process, rhythm, sales volume, market expansion, creation of new customer networks, etc. All such indicators are usually expressed in numbers and are easy to estimate, but how to measure social efficiency indicators: Teamwork, employee collectivism, their attitude towards personal and professional growth, high-quality relationships with each other, are quite difficult to assess. This is why more and more attention is being paid to the use of intangible assets, particularly the utilization of emotional resources, in business. Objectives: To identify emotions experienced and expressed, to assess the strength of emotional workload in the work process, and to determine how emotions combined with business goals.

Methods/Approach: While conducting and planning the research statistical methods, both on the principle of sampling and non-sampling were included.

Results: Research showed that the effectiveness of the management process is improved if the official leader is recognized by the members of the working group as the leader

Conclusions: In modern conditions of development, the leader is required not only to perform basic managerial functions but also to select the right team, to create the necessary emotional impulse to achieve the set goal. In other words, a modern leader should not only be a leader but should also be an emotional leader.
\end{abstract}

Keywords: Intellectual ratio, emotional ratio, emotion, logic, business

JEL classification: D91, M10, M20

\section{How to Cite:}

Akhvlediani, M., Mushkudiani, Z., Nikabadze, S. (2020). Whether we need emotions in business or not. Access journal, ACCESS Press, 1(1): 72-79. DOI: https://doi.org/10.46656/access.2020.1.1(6)

\section{INTRODUCTION}

In modern business, issues such as cost reduction, profit growth, reaching a consensus with a partner, gaining a competitive advantage, finding ways to solve problems creatively, or improving product quality are becoming more and more important every year. The heads of companies have a big burden on their shoulders to solve these problems. Especially when the methods of increasing the efficiency of the company are getting older every year. In such a situation, the effectiveness of business relationships depends on the timely fulfilment of the goals set by the company's executives (Galanina et al, 2017; Shamilishvili, 2019; Zaverbnyj, Redina, \& Matseliukh, 2019; Kurmanov et al, 2018; Petrova et al, 2020). Mainly the goals that are achieved 
by the joint efforts of the employees of the organization. Successful work in a team, of course, depends on the ability of employees to do their job efficiently and consistently. At the present stage of business development, abstract and obscure theses such as "teamwork", "improving communication skills", "focusing on results" and "striving for development" not only instead of motivating employees, irritate them. A clearer algorithm of action needed: what, how, and when to do in order to develop organizational efficiency growth methods and rise to a new level.

Modern areas of applied psychology, including management psychology, traditionally distinguish two main groups of organizational efficiency indicators: productivity and socio-psychological (Cherniss \& Adler, 2000). Productivity indicators, volume, and quality of manufactured products, the intensity of production process, rhythm, sales volume, market expansion, creation of new customer networks, etc. All such indicators are usually expressed in numbers and are easy to estimate, but how to measure social efficiency indicators: Teamwork, employee collectivism, their attitude towards personal and professional growth, high-quality relationships with each other, are quite difficult to assess (Arsawan, 2019; Baklanova, Petrova \& Koval, 2020; Drobnic, Toros \&Weis, 2020; Gechbaia, Kharaishvili \& Mushkudiani, 2019). This is why more and more attention is being paid to the use of intangible assets, particularly the utilization of emotional resources, in business.

Human life is full of a variety of emotions, but all of them are directly derived from the basic emotion or represent a combination of several basic emotions. Many academic papers scientifically research emotions (Barsade \& Gibson, 1999).

Well-known psychologist and emotional researcher Paul Eckman focuses on seven basic emotions (interest, joy, sadness, anger, disgust, fear, and surprise) (Ekman, 2003) Theorist Robert Pluchik discusses initial eight emotions and a whole range of similar emotions (Plutchik, 2001). According to Plushik's theory, emotions are evolutionary mechanisms that play an important role for humans to adapt and survive in the external world. According to this view, the function of each emotion is to stimulate adaptive behavior: emotion is followed by a natural impulse that is expressed in a particular behavior. These mechanisms are genetically determined and work automatically - managing and pushing people to respond to external stimuli. There are 8 main (prototypical) emotions: Anger, fear, sadness, joy, disgust, surprise, confidence, and interest. The model of basic emotions is not only an interesting and curious theory but also helps people understand their psychoemotional dynamics and self-organize. Taking this mode into consideration businesses can more productively use impulses emanating from employees 'emotions redistribute energy resources in the required direction.

According to D. Goleman, a professor at Harvard University, the great revolution of the 21 st century is the revenge of the senses on the intellect (Boyatzis, Goleman \& Rhee, 2000). If earlier the IQ showed the ability to succeed in a particular professional activity, today it prefers the emotional ratio (EQ). Numerous studies have shown that the best employees are not only "graduates" of prestigious universities, but also people with high emotional intelligence (Gobe, 2001). 
Because they are well aware of other people's emotions and they can manage their emotional field, their behaviour is more adapted to society, they can easily achieve their goals, and overall, they influence a prospect of a long-term partnership with customers. Thus, researching and analyzing emotions in business practice is becoming more and more relevant.

\section{METHODOLOGY}

To identify emotions experienced and expressed, to assess the strength of emotional workload in the work process, and to determine how emotions are combined with business goals, for employees in various companies in the public and private sectors, a marketing survey was conducted by Akaki Tsereteli State University's Business Administration Department. The purpose of the survey was to ask as many people as possible by the authors. Respondents were workers who are working in different positions in Kutaisi. The questionnaire was based on metric and nominal variables, and most of the questions were close-ended. 342 respondents were interviewed. Respondents selected based on statistical methods, both on the principle of sampling and nonsampling. Care has been taken to ensure all material included in the analyses is anonymous, unattributable and conforms to ethical research guidelines.

\section{RESULTS AND DISCUSSION}

This research specifically focuses on the more subtle forms of emotion, which are harder to detect and respond to the questions:

1. To the question: "Which emotion do you have the most in the process of work" the answers of the respondents were distributed as follows: Anger 12\%, fear 13\%, sadness 9\%, love 27\%, joy 14\%, disgust $4 \%$, surprise $5 \%$, interest $26 \%$. (fig. 1 )

2. To the question "Can you talk openly about emotions and feelings in the company?", a significant part of the respondents (35\%) think that "can not", "emotions are neglected" 30\% of respondents answer, "emotions are suppressed" say $25 \%$ of respondents, $10 \%$ of respondents believe that "Touch" with emotion should not be at all", otherwise you will have problems.

3. Respondents' answers to the question: "What do you think are the consequences of neglecting employees' emotions?" answers were as follows:

"Staff is less loyal to the company" (12\%). The work environment is stressful (12\%), employees often get sick "on a nervous basis" (12\%).

4. It was interesting to find out how employees feel after work hours. The majority of respondents (31\%) say, they are "tired and unenergetic," after the end of the work hours, $20 \%$ of the respondents think that they are "more emotionally and mentally tired, rather than physically". $6 \%$ of respondents answer: "Work emotions interfere with personal relationships." "Positive emotion follows me from work" admits only $7 \%$ of respondents. 


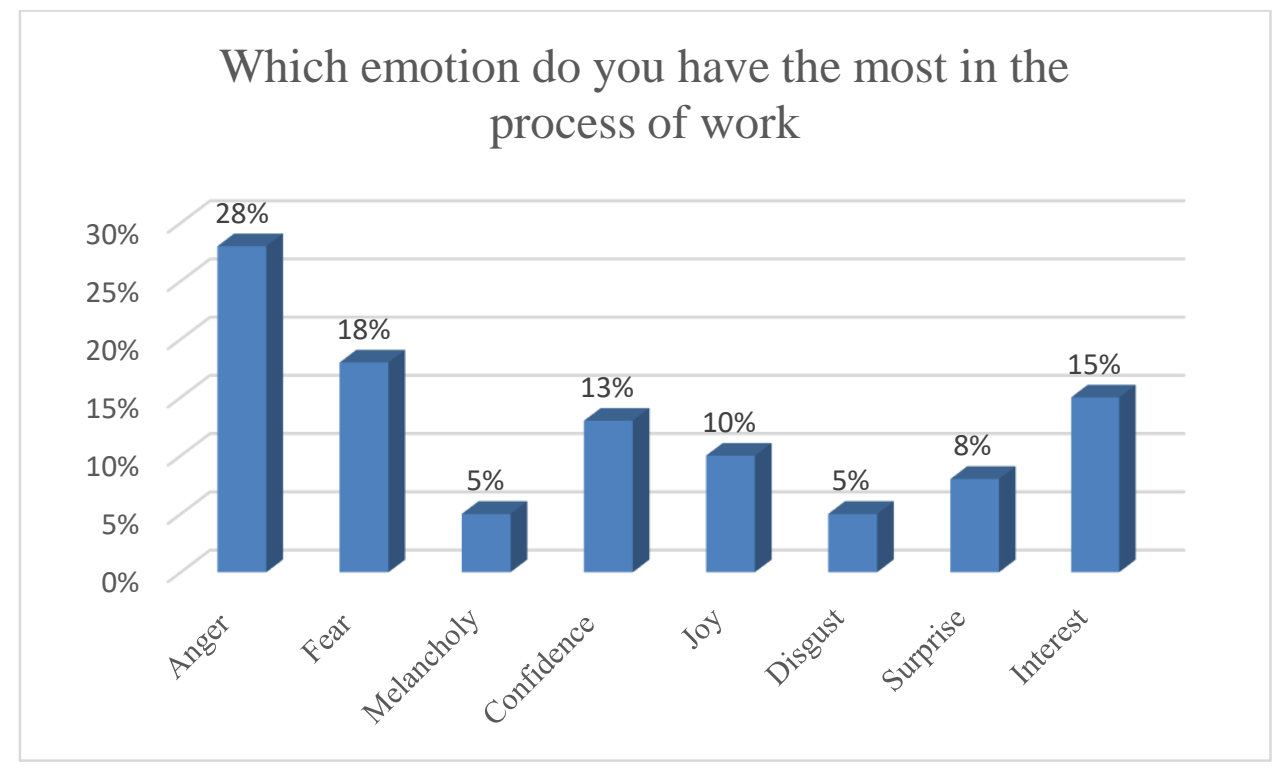

Figure 1. Emotions in the process of work

Source: Own computations

5. The question: "Name the causes of stress" offered 17 options for answers. The first five answers to causes of stress are:

"Low living standards" (12\%), "Routine life with little emotion" (27\%), "Lack of money and various bank debts" (15\%), "Conflict situations with employees and other people" (12\%), "Impossibility of quality rest" (20\%), "Chronic diseases" (4\%), "Excessive physical and mental load" (10\%).

6. To the question: In your opinion, what kind of emotions do the managers of the company express in their relationship with their subordinates?

Anger emotion (28\%), fear (18\%), melancholy (5\%), joy (10\%), disgust (5\%), surprise (8\%), confidence (13\%) and interest (15\%). (fig.2)

Particularly alarming is the fact that the emotions of anger prevail in the emotions expressed by the subordinates of the managers. Clearly, anger produces only aggression and fear, which in turn causes stress. Stress is nothing more than an excessive state of emotion of expectation or fear. As research shows, stress factors can be divided into two groups: organizational factors associated with working in a company and personal factors related to the personal lives of employees. We believe that stress is an unavoidable condition for the development of a business, but managers need to be able to identify the factors that cause stress, come up with protective mechanisms in a timely manner, and manage stress effectively. 


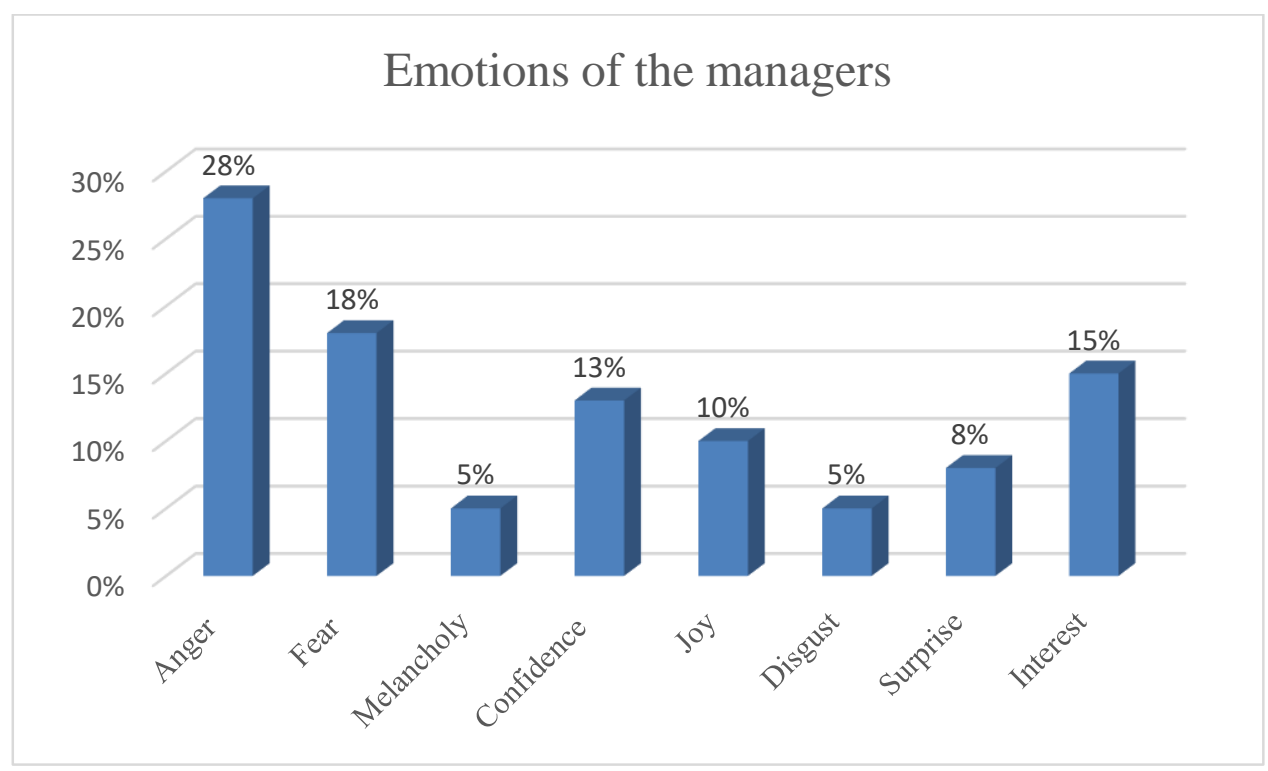

Figure 2. Emotions of the managers of the company express in their relationship with their subordinates

Source: Own computations

7. To the question "How do you think the company's microclimate will change based on the open expression of emotions and proper management of emotions?", "Employee interaction process will be effective" answer $18 \%$ of respondents, management decisions will be adequate - $27 \%$, work productivity will increase $-20 \%$, working microclimate will become positive $-18 \%$, conflicts will decrease - $17 \%$ (Fig.3).

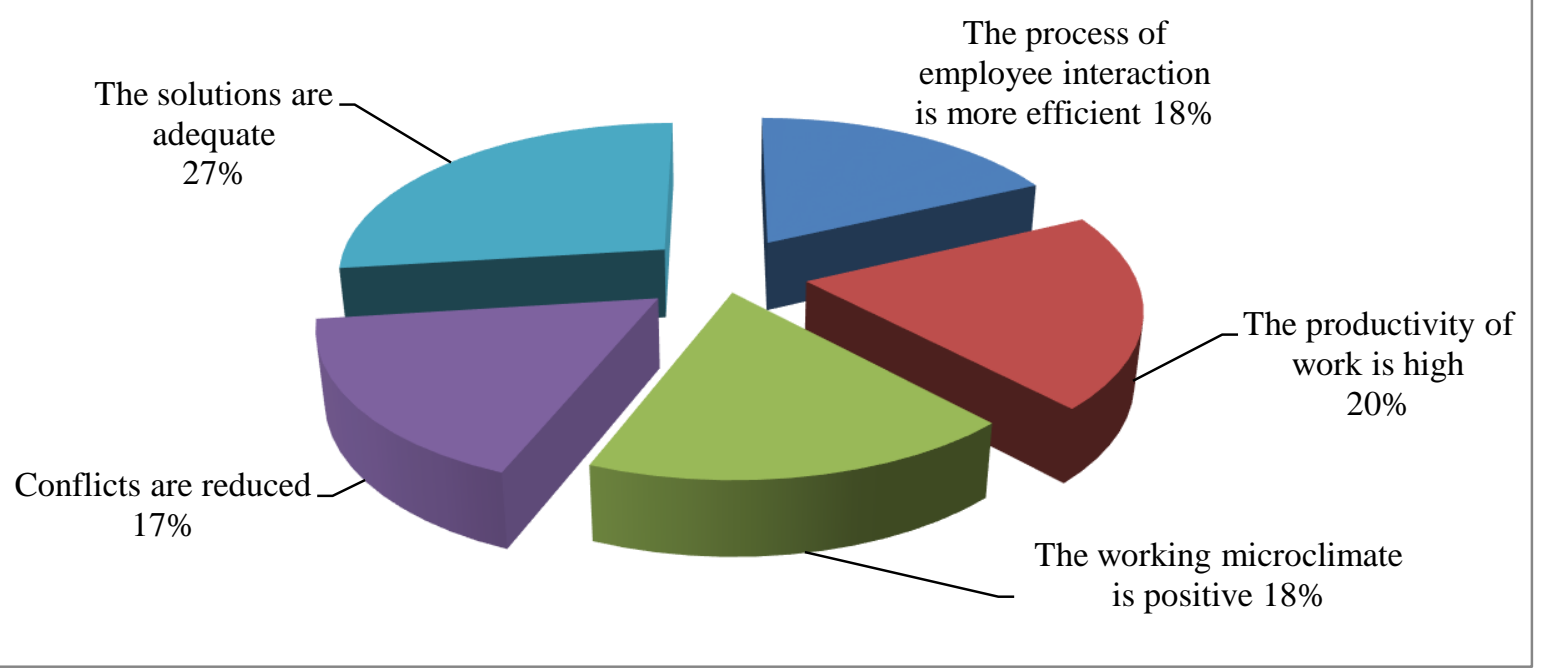

Figure 3. Emotions and the efficiency of the work of companies

Source: Own computations 
The research confirms that the topic of emotional management and emotional intelligence is quite new in Georgian business practice, so it is advisable to train employees in managerial positions in business fields to develop emotions and emotional knowledge and skills, to achieve emotional and intellectual growth. Managers who ignore the emotional component of management spend a lot of energy and health on artificial "masks", but they lose important information about themselves and the outside world. At the same time, the basis for all kinds of long-term cooperation is the understanding of others, their goals, and their values. The relationship between trust and organisational performance has been proven in a number of previous studies, so it can be stated that informal knowledge/information sharing (workplace gossip) with false information adversely affects organisation trust, and, through it, organisational performance. Using well-chose indicators and parameters, the economic consequences can be quantified, which will be presented in a later study.

The research also highlighted that, although formal information/knowledge sharing within organisational functioning is more typical, (thanks to Operational Regulations and Organisational Policies), than the informal mode, people very often are emotional at work. Even if the results make you aware of the negative effects of such informal ways of information/knowledge sharing on the development of culture, emotional relationships, organisational operation, performance and effectiveness.

\section{CONCLUSION}

The study showed that the effectiveness of the management process improved if the members of the working group as the leader recognize the official leader. In modern conditions of development, the leader is required not only to perform basic managerial functions but also to select the right team, to create the necessary emotional impulse to achieve the set goal. In other words, a modern leader should not only be a leader but should also be an emotional leader.

Every day managers get huge amounts of information, the volume of which is constantly increasing.It is impossible to say that emotion and emotionality are better than logic and rationality, however, the results of the study completely deny the generally accepted view that emotions should be completely excluded from business activities, moreover, close, coordinated mental work with emotions can improve not only the professional, communicative and social skills of employees, but also meet and maintain the high level of customer needs.

The emotion inherent in the work did impact on service providers. Occasionally felt mood differed from that which respondents were able to display and they had to suppress their own feelings while caring for or managing the emotions of others.

\section{Conflict of interests}

The authors declare no conflict of interest. 


\section{References}

Arsawan, I. W. E. (2019). Intellectual Capital and Innovation Culture: Evidence from SMEs Performance in Indonesia. Economics. Ecology. Socium, 3, 10-18.

Baklanova, O., Petrova, M., Koval, V. (2020). Institutional transmission in economic development, Ikonomicheski Izsledvania (Economic Studies), 29(1), pp. 68-91

Barsade, S., Gibson, D. (1999) Group emotion” A view from top and bottom, in D. Gruenfeld, B. Mannix and M. Neale (eds.) Research on Managing Groups and Teams. Greenwich, CT: JAI Press.

Boyatzis, R., Goleman, D., and Rhee, K. (2000). Clustering competence in emotional intelligence: Insights from the emotional competence inventory (ECI). In R. Bar-On and J.D.A. Parker (Eds.), Handbook of emotional intelligence. San Francisco: Jossey-Bass.

Cherniss, C. and Adler, M. (2000). Promoting Emotional Intelligence in Organizations. Alexandria, Virginia: ASTD.

Damasio, A. (1994). Descartes' error: Emotion, reason, and the human brain. New York: Grosset/Putnam.

Drobnic, J.; Toros, J.; Weis, L. (2020). Ethical Paradigms in Business and Society. Economics. Ecology. Socium 4, 1-14.

Ekman, P. (2003) Emotions Revealed, Recognizing Faces and Feelings to Improve Communication and Emotional Life, New York

Galanina, T.V., Baumgarten, M.I., Mikhailov, V.G., Koroleva, T.G., Mikhailov, G.S. (2017). Environmental-SocioEconomic Monitoring as a Tool of Region's Environmental-Economic System Management. IOP Conference Series: Earth and Environmental Science. 50(1),012030

Gechbaia, B.; Kharaishvili, E.; Mushkudiani, Z. (2019). The Trends of Producing Agro-Food Products and Export Innovative Marketing Strategy in Georgia. Economics. Ecology. Socium 3, 1-10.

Gobe, M. (2001) Emotional Branding the New Paradigm for Connecting Brands to People. - New York: Allworth Press.

Grant, P. (2005), Business Psychology in Practice. London

Kurmanov N.A., Toksanova A.N., Mukhamedzhanov A.A., Syrlybayeva N.Sh., Petrova, M.M. (2018). Analysis of efficiency of innovation activities in the countries of the Eurasian Economic Union. The Journal of Economic Research \& Business Administration, [S.1.], v. 126, n. 4, p. 35-51, 2018. eISSN 2617-7161. AL-FARABI KAZAKH NATIONAL UNIVERSITY, Available at: https://be.kaznu.kz/index.php/math/article/view/2026

Petrova, M., Koval, V., Tepavicharova, M., Zerkal, A., Radchenko, A., Bondarchuk, N. (2020). The interaction between the human resources motivation and the commitment to the organization. Journal of Security and Sustainability Issues, 9(3): 897-907. https://doi.org/10.9770/jssi.2020.9.3(15)

Plutchik, R. (2001) The Nature of Emotions: Human emotions have deep evolutionary roots, a fact that may explain their complexity and provide tools for clinical practice. American Scientist Vol. 89, No. 4

Shamilishvili, G. (2019). Psychological Influence of Modern Mass Media on Formation of Gender Stereotypes. Economics. Ecology. Socium, 3, 71-76.

Zaverbnyj, A.; Redina, Y.; Matseliukh, Y. (2019). Role Differentiation of Leadership Knowledge and Its Assessment Tools. Economics. Ecology. Socium, 3, 62-70.

\section{About the authors}

\section{Maia AKHVLEDIANI}

PhD in Economics. Professor at Akaki Tsereteli State University. Her current research interests include Marketing and Management, also The Art of Branding. She has been taking part in different scientific and educational conferences.

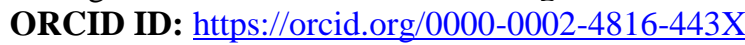

\section{Zurab MUSHKUDIANI}

Professor Mushkudiani is a leading researcher at Batumi Navigation Teaching University. He received his PhD from Akaki Tsereteli State University in 2015 and has worked on plenty of local and international educational projects. 
Also, he worked in Kutaisi City Hall as a PR senior specialist and maintained relationship with public. His specialties are Management, Finance and Education.

ORCID ID: $\underline{\text { https://orcid.org/0000-0003-0987-3564 }}$

\section{Sophiko NIKABADZE}

Professor at Akaki Tsereteli State Univeristy (Kutaisi, Georgia), PhD in Business Administration from Akaki Tsereteli State Univeristy (Georgia), Current research interests include HR Management. Innovative Management and Project Management.

ORCID ID: $\underline{\text { https://orcid.org/0000-0002-7001-8033 }}$

Copyright (C) 2020 by author(s) and ACCESS Publishing Press

This work is licensed under the Creative Commons Attribution International License (CC BY). 